Please do not remove this page

RMIT

UNIVERSITY

\title{
The influence of the wall cavity on the transmission loss of wall systems - experimental trends
}

Cambridge, Jason; Davy, John; Pearse, John

https://researchrepository.rmit.edu.au/esploro/outputs/9921859231001341/filesAndLinks?institution=61RMIT_INST\&index=null

Cambridge, J., Davy, J., \& Pearse, J. (2013). The influence of the wall cavity on the transmission loss of wall systems - experimental trends. Building Acoustics, 20(2), 87-106.

https://doi.org/10.1260/1351-010X.20.2.87

Document Version: Published Version

Published Version: https://doi.org/10.1260/1351-010X.20.2.87

Repository homepage: https://researchrepository.rmit.edu.au

(c) 2013 Multi-Science Publishing

Downloaded On 2023/04/27 01:28:07 +1000

Please do not remove this page 
Thank you for downloading this document from the RMIT Research Repository.

The RMIT Research Repository is an open access database showcasing the research outputs of RMIT University researchers.

RMIT Research Repository: http://researchbank.rmit.edu.au/

\section{Citation:}

Cambridge, J, Davy, J and Pearse, J 2013, 'The influence of the wall cavity on the transmission loss of wall systems - experimental trends', Building Acoustics, vol. 20, no. 2 , pp. 87-106.

See this record in the RMIT Research Repository at:

http://researchbank.rmit.edu.au/view/rmit:22679

Version: Published Version

Copyright Statement: (C) 2013 Multi-Science Publishing

Link to Published Version:

http://dx.doi.org/10.1260/1351-010X.20.2.87 


\title{
The Influence of the Wall Cavity on the Transmission Loss of Wall Systems - Experimental Trends
}

\author{
Jason E. Cambridge ${ }^{1}$, John L. Davy ${ }^{2,3}$ and John Pearse ${ }^{1}$ \\ ${ }^{1}$ University of Canterbury, Mechanical Engineering, Private Bag 4800, Christchurch \\ 8140, New Zealand, \\ jasoncambridge@hotmail.com,john.pearse@canterbury.ac.nz \\ ${ }^{2}$ School of Applied Sciences, Royal Melbourne Institute of Technology (RMIT) \\ University, GPO Box 2476V Melbourne, Victoria 3001, Australia, \\ john.davy@rmit.edu.au \\ ${ }^{3}$ CSIRO Materials Science and Engineering, PO Box 56 Highett, Victoria 3190, \\ Australia, \\ john.davy@csiro.au
}

(Received 6 June 2013 and accepted 2 September 2013)

\begin{abstract}
Numerous experimental investigations have been conducted into the sound transmission loss of double leaf wall systems. From these investigations, it has been observed that the properties of the wall panels, material placed within the wall cavity as well as the type of wall connections used, greatly influence the sound transmission through the wall system. In all of these cases the wall cavity greatly affects the extent of this influence and in some cases it can even nullify their effect when changes are made. In this paper the influence of the wall cavity based on experimental trends is investigated. The investigation revealed that a wide variety of conclusions were obtained by different researchers concerning the role of the cavity and the properties of any associated sound absorption material on the sound transmission loss through double leaf wall systems. Consequently recommendations about the ways in which sound transmission through cavity systems can be improved should always be qualified with regard to the specific frequency range of interest, type of sound absorption material, wall panel and stud characteristics.
\end{abstract}

\section{INTRODUCTION}

Numerous experimental investigations have been conducted into the sound transmission loss (STL) of wall systems. It has been observed that the amount, location and properties of the sound absorption material placed within the cavity directly affect the resonant component of sound transmission. Consequently, characteristics such as the damping of the modes within the cavity as well as the extent of modal coupling between the panels and wall cavity are directly influenced by the amount, location and properties of the sound absorption material placed within the wall cavity. On the other hand the size of the cavity directly affects the resonance frequencies, pressure distribution as well as the position of the axial, tangential and oblique modes. 
A quantitative comparison of the numerous experimental investigations by different researchers is difficult due to the differences which occur in experimental laboratory facilities and measurement technique. Fausti et al. [1] conducted round robin tests and showed that differences up to $12 \mathrm{~dB}$ can occur between measurements in the midfrequency range; while comparisons between the intensity and conventional two room method showed that differences do occur between these two measurement techniques especially in the low frequency range as discussed by Jacobson and Ding [2], Ding and Jacobson $^{3}$ and Lai et al. [4] among others. Consequently these differences make absolute quantitative comparison of the experimental data difficult. However, a qualitative comparison of the conclusions obtained from the experiments conducted by different researchers can be carried out.

This paper summarizes the significant experimental observations and conclusions made by different researchers concerning the influence of the wall cavity and any associated sound absorption material on the STL of double leaf wall systems. The analysis is based on three distinct frequency ranges:

- Low frequency range, above the mass air mass resonance frequency $\left(f_{0}\right)$ but below the limiting frequency $\left(f_{l}\right)$

- Middle frequency range, above the limiting frequency but below the critical frequency, $\left(f_{c}\right)$

- High frequency range, above the critical frequency.

The influence of the material's airflow resistance, density, thickness to cavity depth ratio, amount and location as well as the type of material and size of the cavity on the STL with respect to these frequency ranges will be addressed. A summary of reported work used during this discussion as well as the specific areas investigated can be seen in Table 1. It should be noted that throughout this discussion the generic name of the materials will be used instead of the trade names; for example mineral-wool will be used to refer to rock-wool and glass-fibre for fibreglass. As a result the names of the materials used in the original documents by the authors listed in Table 1 may be different from those used in this analysis.

\section{AIRFLOW RESISTANCE}

The acoustic behaviour of porous acoustic material is governed by its five physical parameters which include its porosity, airflow resistivity, tortuosity, viscous characteristic length and thermal characteristic length [5]. Of the five physical parameters, standardized tests are only currently available for measuring the airflow resistivity and porosity [5]. As a result it is not surprising that airflow resistivity has been used extensively to describe the sound absorption properties of the materials placed within the wall cavity.

Mathematical studies have shown that when porous sound absorbent material is placed within the wall cavity an airflow resistivity of approximately 5000 to 10000 $\mathrm{Ns} / \mathrm{m}^{4}$ is needed to achieve maximum damping of the modes within the cavity [6]. The results of these mathematical studies were verified by Gösele's [6] measurements whichindicated that increasing the airflow resistivity from 6500 to $28000 \mathrm{Ns} / \mathrm{m}^{4}$ resulted only in a slight improvement in the STL. On the other hand, Narang' ${ }^{[7]}$ experimental investigations with glass-fibre within the wall cavity suggested that an 
Table 1: Reported experimental investigations

\begin{tabular}{|c|c|c|c|c|c|c|c|c|}
\hline \multirow[t]{2}{*}{ Author } & \multirow[t]{2}{*}{ Year } & \multicolumn{5}{|c|}{ Sound Absorption Material Properties } & \multicolumn{2}{|c|}{$\begin{array}{c}\text { Cavity } \\
\text { Parameters }\end{array}$} \\
\hline & & $\begin{array}{l}\text { Airflow } \\
\text { resistivity }\end{array}$ & $\begin{array}{c}\text { Thickness } \\
\text { to Cavity } \\
\text { Depth Ratio }\end{array}$ & Amount & Density & Type & Location & Size \\
\hline Meyer & 1935 & & & & & & $\checkmark$ & \\
\hline London & 1950 & & & $\checkmark$ & & & & $\checkmark$ \\
\hline Ingerslev & 1952 & & & & & & $\checkmark$ & \\
\hline Bazley & 1966 & & & $\checkmark$ & & & & \\
\hline Ford & 1967 & & & $\checkmark$ & & & $\checkmark$ & \\
\hline Zaborov & 1967 & & & & & & & $\checkmark$ \\
\hline Utley & 1968 & & & & & & & $\checkmark$ \\
\hline Northwood & 1968 & & $\checkmark$ & & $\checkmark$ & $\checkmark$ & & \\
\hline Utley & 1969 & & & $\checkmark$ & & & $\checkmark$ & \\
\hline Loney & 1971 & & $\checkmark$ & $\checkmark$ & $\checkmark$ & $\checkmark$ & $\checkmark$ & $\checkmark$ \\
\hline Mulholland & 1971 & & & $\checkmark$ & $\checkmark$ & $\checkmark$ & & $\checkmark$ \\
\hline Loney & 1973 & & $\checkmark$ & & & $\checkmark$ & & $\checkmark$ \\
\hline Gösele & 1977 & $\checkmark$ & & $\checkmark$ & & & $\checkmark$ & \\
\hline Green & 1982 & & & $\checkmark$ & & & & $\checkmark$ \\
\hline Novak & 1992 & $\checkmark$ & $\checkmark$ & $\checkmark$ & & $\checkmark$ & & \\
\hline Quirt & 1993 & $\checkmark$ & $\checkmark$ & $\checkmark$ & & $\checkmark$ & $\checkmark$ & \\
\hline Narang & 1993 & $\checkmark$ & $\checkmark$ & & $\checkmark$ & & & \\
\hline Warnock & 1995 & $\checkmark$ & $\checkmark$ & & & $\checkmark$ & & \\
\hline Narang & 1995 & $\checkmark$ & & & $\checkmark$ & $\checkmark$ & & \\
\hline Bolton & 1996 & & & & & & $\checkmark$ & \\
\hline Uris & 1999 & & & & $\checkmark$ & & & \\
\hline Uris & 2000 & & $\checkmark$ & & $\checkmark$ & & & \\
\hline Uris & 2001 & & $\checkmark$ & & & & & $\checkmark$ \\
\hline Kurra & 2001 & & $\checkmark$ & $\checkmark$ & $\checkmark$ & & & $\checkmark$ \\
\hline Hongisto & 2002 & $\checkmark$ & $\checkmark$ & $\checkmark$ & $\checkmark$ & & & \\
\hline Royar & 2007 & $\checkmark$ & $\checkmark$ & $\checkmark$ & $\checkmark$ & & & \\
\hline
\end{tabular}

airflow resistance of $500 \mathrm{Ns} / \mathrm{m}^{3}$ is sufficient to damp the cavity vibration modes provided that the cavity is nearly completely filled with glass-fibre. Experimental investigations conducted by Royar ${ }^{[8]}$ with mineral-wool as an infill also indicated that the damping limit is reached once the airflow resistivity of $5000 \mathrm{Ns} / \mathrm{m}^{4}$ is obtained. Furthermore experimental investigations conducted by Narang [9] with polyester infill showed that STL values similar to when glass-fibre was used can be obtained even though the airflow resistivity of polyester was $20 \%$ less than glass-fibre. Narang [9] 
also observed that small changes in the airflow resistivity had only a minor effect on the STL; thus confirming Gösele's observation [6].

Although both Narang's [7] and Royar's [8] suggestion for the required airflow resistivity is supported by Gösele's [6] observation based on mathematical studies; other experimental investigations provide additional insight into the effect of the airflow resistivity on the STL. Novak [10] measured the STL with different infills within the cavity with different densities and airflow resistivities. These infill materials included one glass-wool, four different mineral-wool, one cellulose and two polyethylene/dacron materials. All of the materials except cellulose produced a similar STL within the low frequency range. The STL with the cellulose material as an infill was lower than the others even though its density $\left(50 \mathrm{~kg} / \mathrm{m}^{3}\right)$ and its airflow resistivity $\left(9700 \mathrm{Ns} / \mathrm{m}^{4}\right)$ were higher than some of the other materials investigated. Novak [10] indicated that this observation could not be explained from either its density or airflow resistivity. For the middle and high frequency ranges Novak [10] obtained similar STL values for cavity infills with airflow resistivity greater than $5000 \mathrm{Ns} / \mathrm{m}^{4}$ : In these frequency ranges the STL of the wall system increased as the airflow resistivity of the infill material was increased for materials with airflow resistivity less than $5000 \mathrm{Ns} / \mathrm{m}^{4}$. Novak's [10] results for the middle and high frequency ranges agree with both Narang's [7] and Royar's [8] supposition that an airflow resistivity of at least $5000 \mathrm{Ns} / \mathrm{m}^{4}$ is needed to sufficiently damp the modes within the cavity.

Novak's [10] work was conducted at the Royal Institute of Technology in Sweden; interestingly Quirt [11] and Warnock's [12] work which was conducted at the National Research Council of Canada and showed a slightly different trend to Novak. Quirt [11] measured the STL of a $3 \mathrm{~mm}$ plastic double leaf wall with a cavity depth of $150 \mathrm{~mm}$ with seven different $100 \mathrm{~mm}$ thick fibrous material cavity infills. No significant correlation occurred between the STL and the material's airflow resistivity or density for both the high and low frequency ranges. However, for the mid frequency range (i.e. 500 to $2000 \mathrm{~Hz}$ ) the r-squared correlation was between 0.8 to 0.9 for the airflow resistivity but below 0.4 for the density. As a result Quirt concluded that these results suggested that the airflow resistivity, rather than the density is a significant characteristic which determines the effectiveness of the absorptive material placed within the cavity.

On the other hand Warnock [12] measured and took multiple regression lines from 360 wall tests containing sound absorption material and studied the dependence of both the STC and $R_{w}^{\prime}$ on the mass of the gypsum board layers $\left(M_{g}\right)$, cavity depth $(d)$, airflow resistance $(R)$ and stud spacing $\left(S_{o c}\right)$. The resulting equations for these regression lines were;

$S T C=-69.8+33.5 \log _{10} \mathrm{M}_{\mathrm{g}}+32.2 \log _{10} d-7 \times 10^{-4} R+0.017 S_{o c}, r^{2}=0.903$

and

$R_{w}^{\prime}=-60.3+29.5 \log _{10} \mathrm{M}_{\mathrm{g}}+32.2 \log _{10} d-2.1 \times 10^{-4} R+9.2 \times 10^{-3} S_{o c}, r^{2}=0.924$

The negative correlation between both the STC and $R_{w}^{\prime}$ and the airflow resistance (R) from these regression lines was apparent and surprising. Warnock [12] gave two plausible explanations for this occurrence. Firstly, for the low frequency range both 
the mineral fibre and cellulose fibre material performed poorly; this could be due to the fact that for some of the materials used the increase in airflow resistance also increased its density and rigidity therefore an increase in the structural transmission through the material was possible. Secondly, at $2000 \mathrm{~Hz}$ and above Warnock suspected that the dominance of the structural transmission through the resilient metal stud or channel over the airborne sound transmission was the reason for the poor correlation in this range. As a result of the negative correlation obtained for the airflow resistance, Warnock [12] concluded that factors other than the airflow resistance of the material needs to be considered; a conclusion which also agrees with Novak's [10] measured results.

It can be concluded that for the middle and high frequency ranges increasing the airflow resistivity up to approximately $5000 \mathrm{Ns} / \mathrm{m}^{4}$ will lead to an increase in the STL once the structural transmission through the wall system isn't increased due to an increase in the rigidity of the material as a result of the increased airflow resistivity. Once the airflow resistivity goes above approximately $5000 \mathrm{Ns} / \mathrm{m}^{4}$ further increases in the airflow resistivity will lead to little improvement in the STL as most of the modes within the wall cavity are sufficiently damped. Correlation between the STL and the airflow resistance/resistivity is poor for the low frequency range; as a result other factors need to be considered.

\section{DENSITY}

While discussing Quirt's work within Section 2 it became apparent that there was some discussion within the literature about whether the density or airflow resistance/ resistivity of the material in the wall cavity was the important factor which influenced the STL of the wall system. Quirt [11] indicated that the density didn't have a significant effect on the STL since the r-squared correlation between the density and the STL was only 0.4 as opposed to 0.8 for the airflow resistivity within the mid-frequency range (i.e. 500 to $2000 \mathrm{~Hz}$ ). On the other hand Warnock [12] in his final summary indicated that using sound absorption material with high airflow resistivity and density was beneficial for the high frequency range but not for the low frequencies which determine the single rated STC and $R_{w}^{\prime}$. values.

Warnock's [12] conclusion about the effect of the density of the material on the STC ratings is supported by Loney's [13] findings which indicated that slight but significant increase in the STL due to increased density in the mid frequency range was not reflected in the overall STC since this frequency range was not important in determining the STC. Loney [13] used glass-fibre and mineral-wool for the infills of his cavity; his measurement results showed that the STL of the thinnest densest material was less than the thicker sample with equal surface density. Consequently, Loney [13] concluded that the thickness rather than the density of the material is a more reliable general indicator of a material's effect on the STL. Furthermore, Mulholland's [14] investigation showed how unreliable the use of the material's density as the only indicator of the materials effectiveness on the STL can be. Mulholland's [14] results presented in Figure 1 and Figure 2 showed that the lightweight double leaf gypsum plasterboard wall system with denser mineral-wool as an infill, produced higher STL 
than polyurethane or polystyrene as an infill in the 50 and $100 \mathrm{~mm}$ cavity: However, the polyurethane infill produced higher STL than the polystyrene even though the densities of both materials were the same (i.e. 1 and $2 \mathrm{~kg} / \mathrm{m}^{2}$ in the 50 and $100 \mathrm{~mm}$ cavity respectively).

The difference in the STL results with polyurethane and polystyrene, as well as the poor correlation which occurred between the STL and density for a variety of materials as in Quirt's [11] investigation suggests that an analysis of the effect of density based on the specific type of material used within the wall cavity would be beneficial.

Uris et al. [15] utilized a gypsum plasterboard double leaf wall system with a $50 \mathrm{~mm}$ deep cavity and three mineral-wool infills of different densities (120, 70 and $40 \mathrm{~kg} / \mathrm{m}^{3}$ ). Uris showed that below the mass air mass resonance frequency (i.e. $f_{0}=125 \mathrm{~Hz}$ ) the $120 \mathrm{~kg} / \mathrm{m}^{3}$ mineral-wool performed better than the 70 and $40 \mathrm{~kg} / \mathrm{m}^{3}$ infills as shown inFigure 3 .

Uris et al. [15] concluded that this trend occurred because the lower density mineralwool didn't have sufficient inertia to remain motionless under the excitation of the sound waves and the effect of the mineral-wool was to provide resistance and mass inertia to the sound waves passing through it. Within the middle frequency range (i.e. 125 to $1250 \mathrm{~Hz}$ ) the $120 \mathrm{~kg} / \mathrm{m}^{3}$ mineral-wool performed significantly worse than the 70 and $40 \mathrm{~kg} / \mathrm{m}^{3}$ mineral-wool; with the less dense $40 \mathrm{~kg} / \mathrm{m}^{3}$ mineral-wool performing slightly better than the $70 \mathrm{~kg} / \mathrm{m}^{3}$ sample. Little difference occurred for the STL in the middle and high frequency range. On the other hand, Royar's [8] experimental results with the density of mineral-wool varied from 18 to $125 \mathrm{~kg} / \mathrm{m}^{3}$ showed that increasing the density of the cavity infills did not result in an increase in the STL for all frequency

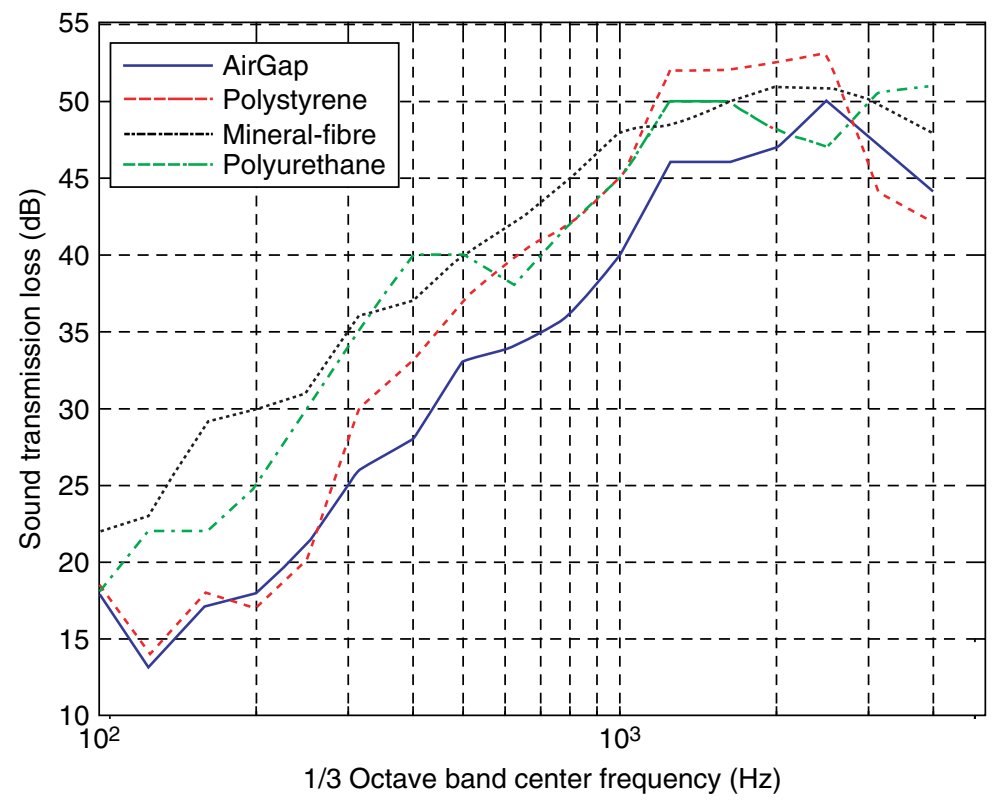

Figure 1. Mulholland's (1971) measured STL through a double leaf gypsum wall system with various infills; leaf thickness $11 \mathrm{~mm}$; cavity depth $50 \mathrm{~mm}$. 


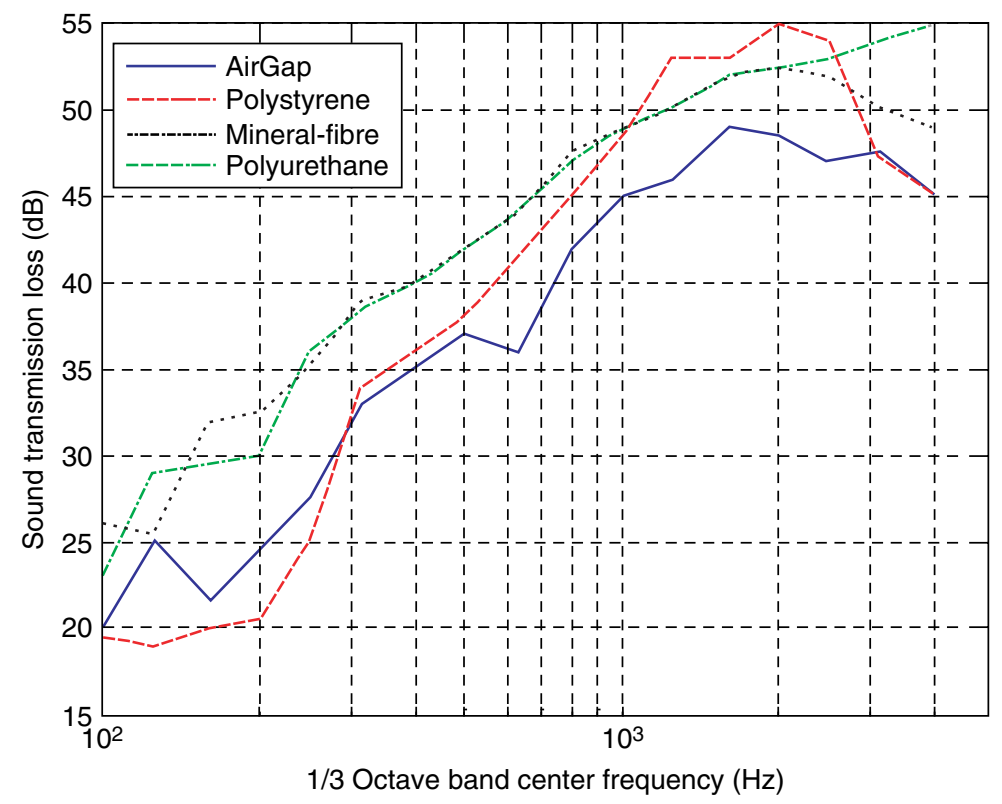

Figure 2. Mulholland's (1971) measured STL through a double leaf gypsum wall system with various infills; leaf thickness $11 \mathrm{~mm}$; cavity depth $100 \mathrm{~mm}$.

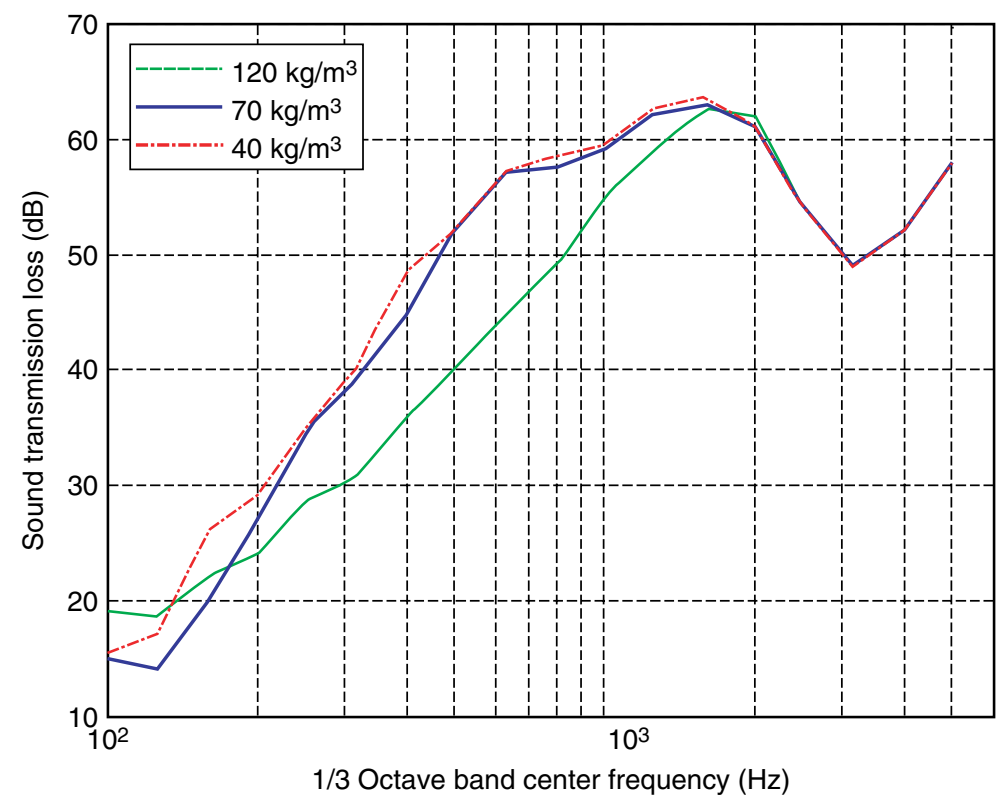

Figure 3. Uris et al. (1999) measured STL through a $13 \mathrm{~mm}$ gypsum plasterboard double leaf wall system with $50 \mathrm{~mm}$ cavity depth and mineral-wool infills of diffrent densities. 
ranges if the airflow resistivity had reached a value of $5000 \mathrm{Ns} / \mathrm{m}^{4}$ Royar [8] noted that a further increase in the density only led to an increase in the cost of production. Furthermore, while investigating the use of mineral-wool and glass-fibre Northwood [16] observed that his results were not critically sensitive to the material's density.

These trends were different from Uris et al.'s [17] investigation using 60, 80 and $120 \mathrm{~kg} / \mathrm{m}^{3}$ dense polyurethane foam as the infill. This investigation showed that within the measured low frequency range (i.e.100 to $315 \mathrm{~Hz}$ ) increasing the density of the polyurethane foam did not increase the STL. However, for the middle and high frequency ranges increasing the density of the polyurethane foam did result in an increase in the STL.

Narang's [7] results with glass-fibre agreed with Northwood's [16] conclusion that the STL was not critically sensitive to the material's density; as his results showed the STC rating exhibited asymptotic behaviour as a function of density and a high density is not required if the STC is the only criteria parameter of interest. No significant improvement occurred in the STC rating beyond a density of approximately $30 \mathrm{~kg} / \mathrm{m}^{3}$ [7]; while Irvine [18] recommended that the density of the sound insulation material should not be less than $40 \mathrm{~kg} / \mathrm{m}^{3}$ Narang's [7] results also showed that the thickness of the material had a significant effect on the STL; and it would be more cost effective to use a $75 \mathrm{~mm}$ thick low density glass-fibre in a $64 \mathrm{~mm}$ cavity than to use a $50 \mathrm{~mm}$ thick high density glass-fibre.

It can be concluded that the effect of the density of the material on the STL is dependent on the type of material used and the frequency range of interest. Similar to the case discussed with regard to the effect of the airflow resistivity/resistance the increase of the density of some materials can result in an increase in their rigidity and may result in an increase in the structure borne transmission. This explains the reason why the correlation between the STL and the density of the material is low when comparisons between different materials are made. A material density of at least approximately $40 \mathrm{~kg} / \mathrm{m}^{3}$ is recommended and the potential increase in production cost by increasing the density of the infill material has been noted. Once an airflow resistivity of $5000 \mathrm{Ns} / \mathrm{m}^{4}$ is obtained, increasing the density will not lead to any significant increase in the STL.

\section{MATERIAL THICKNESS TO CAVITY DEPTH RATIO}

The thickness rather than the density of the material is a more reliable general indicator of a material's effect on the STL [13]. The question however remains; to what degree does the thickness of the material influence the STL.

Novak' ${ }^{[10]}$ experimental results showed that if the ratio of the thickness of the material to cavity depth was less than 0.5 , then the smaller thickness to cavity ratio performed worse than a material with a greater thickness to cavity depth ratio. Novak also noted that no significant increase occurred in the STL after a certain thickness was reached. Loney [13] explained this trend by noting that the STL varies as the logarithm of the thickness rather than linearly; a conclusion which can explain the observed results from other researchers. 
Northwood [16] noted that the STL was not critically sensitive to the thickness while Uris et al.. [17] recognized that increasing the thickness of polyurethane foam from 100 to $150 \mathrm{~mm}$ did not significantly increase the STL below $1000 \mathrm{~Hz}$. The greatest effect was obtained for frequencies above $1000 \mathrm{~Hz}$ where the wavelength of the sound waves in the polyurethane foam became comparable to its thickness [17]. Quirt's [11] measurements on the other hand showed a continual increase in the STL with increasing thickness. Quirt's results were obtained for 50, 100 and $200 \mathrm{~mm}$ thick sound absorption material placed within a $205 \mathrm{~mm}$ cavity. The steady increase in the STL with increasing thickness of the sound absorption material could be due to the ratio of the material thickness to the cavity depth being less than 0.5 in the 50 and $100 \mathrm{~mm}$ case. These results also support Novak's findings with regard to the relationship between the cavity depth and thickness of the material.

In conclusion the STL increases with increased thickness of the material placed within the cavity until a certain thickness to cavity depth ratio is obtained. Once this ratio is obtained, only slight improvement in the STL occurs with an increase in the thickness of the material. Loney summarized this trend by stating that the STL varies as the logarithm of the thickness rather than linearly.

\section{AMOUNT}

The effect of the amount of sound absorption material in the cavity from different experimental investigations is discussed within this section. Ford's [19] experimental investigation showed little difference could be seen between the results obtained for the completely filled and partially filled case; only $1 \mathrm{~dB}$ difference occurred between the overall mean in both cases. The increase in the STL due to the doubling of the amount of sound absorption material within the cavity, can be seen from Bazley's [20] reported results shown in Figure 4.

The results shown in Figure 4 are for a $1 / 4$ inch $(6.35 \mathrm{~mm})$ plywood double leaf wall system with two 2 inch $(50.8 \mathrm{~mm})$ wooden studs at $2 \mathrm{ft}(609.6 \mathrm{~mm})$ centres. Mulholland [14] commented on these results and speculated that it is possible that complete filling of the cavity will not only dampen the cavity resonances, such as the mass spring mass resonance and the various standing waves, but it will also add a degree of damping to the panel resonances and the coincidence effect. On the other hand Quirt [11] viewed the complete filling of the cavity as causing a lateral shift in the STL for the lower frequencies, with the mass air mass resonance frequency shifting to a lower frequency in this case; $\mathrm{Kurra}^{[21]}$ also observed this lateral shift in the mass air mass frequency. This lateral shift in the mass air mass frequency due to the presence of sound absorption material within the cavity can also be seen in Figure 4. Narang [7] gave the explanation for the lateral shift of the mass-air-mass resonance frequency by noting that the presence of glass-fibre makes the compressions and rarefactions at the low frequencies an isothermal process as opposed to an adiabatic process as in air. The resulting reduction in the speed of sound causes the mass-air-mass resonance frequency to shift to a lower frequency.

Loney [13] investigated the effect of various amounts of sound absorption material within the cavity. His results showed that the first initial amount of sound absorption 


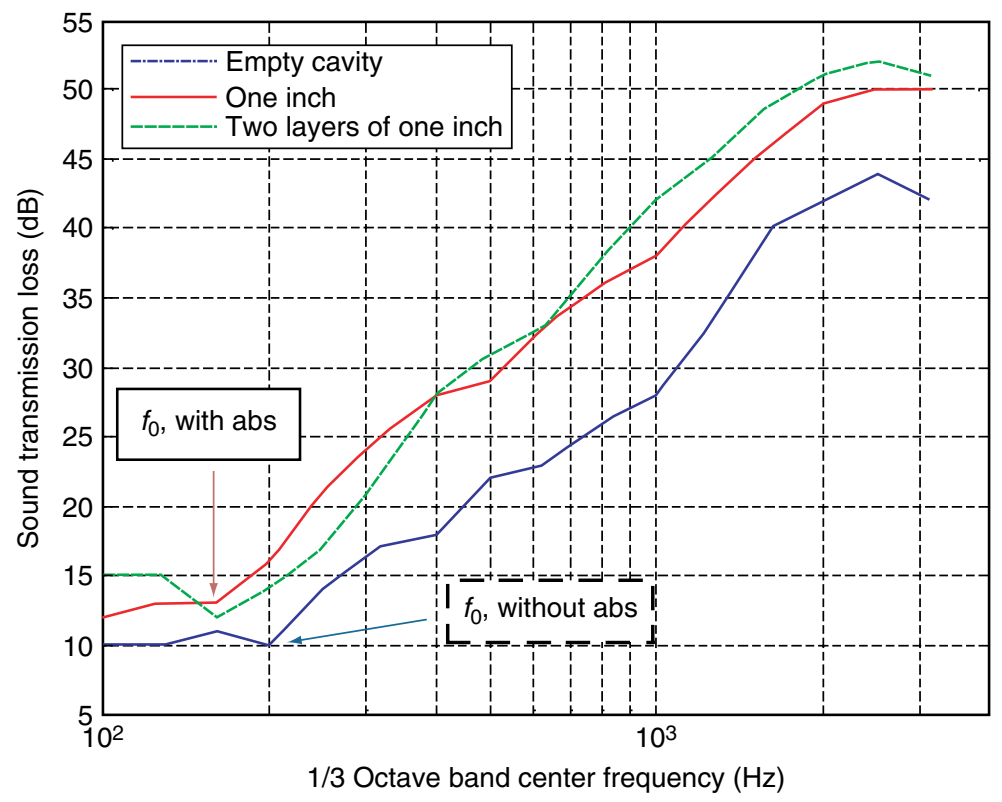

Figure 4. Bazley's (1966) reported results showing the effect of doubling the amount of sound absorption material within a 2 inch $(50 \mathrm{~mm})$ cavity.

material has the greatest effect on the STL. Hongisto [22] verified this trend and noted that increasing the filling ratio (i.e. the ratio of the thickness of the absorbent material to the depth of the cavity) from $0 \%$ to $24 \%$ gave a significantly larger increase in the STL than increasing the filling ratio from $24 \%$ to $88 \%$. Despite the decreased gain in improvement of the STL after the first initial amount is added, as shown by Loney [13] and Hongisto [22], authors such as Quirt [11] indicate that filling the cavity remains the most practical, while Gösele [6] maintains that marginal damping (i.e. partially filling the cavity) is not a complete substitute for the fully damped case (i.e. completely filled). Quirt [11] and Gösele's [6] recommendation agree with Royar's [8] finding that filling even the last $10 \%$ of the cavity improves its performance. However, despite these trends it should be noted that both the effectiveness and the expected amount of improvement in the STL when sound absorption material is added to the cavity is directly dependent on the properties of the wall panels.

Mulholland's [14] investigation showed that sound absorption material added to the wall cavity of the lightweight wall construction improved the STL of the system, but had no effect when heavy panels were used. Uris et al.'s [23] investigation showed how the properties of the wall panels influenced the effect of the sound absorption material placed within the wall cavity. Uris et al. [23] placed mineral-wool within an uncoupled double leaf wall with one, two and three layers of gypsum boards symmetrically placed on each side of the cavity. His results showed a reduction in the influence of the mineral-wool within the cavity on the STL as the number of layers on each side was 
increased. The progressive increase in attenuation through the gypsum boards as the number of layers was increased was the explanation given for the reduced effectiveness of the mineral-wool within the cavity [23].

Green and Cameron [24-26] measured the STL with and without glass-fibre within double leaf gypsum wall systems with steel and wooden studs which were either glued or screwed to the wall panels. Green and Cameron's [23] results for the double leaf wall systems with screwed steel studs showed decreased improvement in the both the STL and STC when glass-fibre was added as the mass of the wall panels were increased. The decrease in the improvement in the STC can be seen from the extracted results shown in Table 2. Although the results shown in Table 2 show that the improvement in the STC was greater when the smaller $0.063 \mathrm{~m}$ stud was used, the trend of the decreased improvement in the STC is evident for both the 0.063 and $0.092 \mathrm{~m}$ stud size. As a result of these observations Green and Cameron [25] concluded that the heavier and stiffer the wall, the smaller the increase in the STL when glass-fibre is added to the cavity (i.e. with steel studs).

A slightly different trend occurred in the results of Green and Cameron [26] with wooden studs as shown in Table 3 . These results show no increased improvement in the STC as the mass of the wall panels was increased when the wooden studs were screwed to the wall panels; as opposed to a slight increase in the improvement when the wooden studs were glued to the panels. Consequently, Green and Cameron [26] concluded that the cavity infills were more effective in multilayer partitions having a second layer attached to the first with adhesive than if screws were used.

It should be noted that increasing the thickness of the panels of a lightweight double wall construction does not lead to a major increase in the STC when sound absorption material is added to the cavity. Although increasing the thickness of the wall panel leads to an increase in its mass, which based on the mass law leads to an increase in the STL, an increase in the thickness of the wall panel also leads to a decrease in the critical frequency. The effect of the increased mass and the decrease in the critical frequency often leads to similar $\mathrm{STC}$ or $R_{w}$ values when comparing the $\mathrm{STL}$ of single panels which differ in thickness. On the other hand for double leaf wall constructions, the thickness of the wall panels only has a significant effect on the STC when there is no sound absorption material present within the cavity. This trend was observed by Loney [27] when he reported a 3 STC increase when the size of his single panels in his double wall was increased from $1 / 2$ inch $(12.7 \mathrm{~mm})$ to $5 / 8$ inch $(15.9 \mathrm{~mm})$; but no increase in the STC when sound absorption material was added to the cavity. A similar trend can be seen from the reported results by Halliwell et al. [28] in Figure 5. These results show the expected decrease in the critical frequency, but little difference occurs within the low and middle frequency regions for the different thicknesses. This resulted in a $1 \mathrm{~dB}$ decrease in the STC for the $16 \mathrm{~mm}$ gypsum plasterboard wall system as shown.

In conclusion the amount of sound absorption material needed within the wall cavity for optimum STL is dependent on the properties of the individual wall panels and the type of connections used. The recommendation by some authors of completely filling the wall cavity of lightweight double leaf wall systems has been noted. However, for heavy double leaf wall systems the effectiveness of the sound absorption material and 
Table 2: Extracted results from Green and Cameron [24 25] showing the improvement in STC rating when glass-fibre is added to the wall cavity with steel studs as the mass of the wall panels is increased

\begin{tabular}{lccc}
\hline Surface density $\frac{\mathrm{kg}}{\mathrm{m}^{2}}$ & STC without absorption & STC with absorption & Increase in STC \\
\hline 19 & 37 & 0.092 m steel stud partition & \\
29 & 43 & 44 & 7 \\
39 & 47 & 53 & 6 \\
49 & 51 & 55 & 4 \\
19 & 36 & 44 & 8 \\
29 & 42 & 49 & 7 \\
39 & 46 & 52 & 6 \\
49 & 49 & 54 & 5 \\
\hline
\end{tabular}

Table 3: Extracted results from Green and Cameron [26] showing the improvement in STC rating when glass-fibre is added to the wall cavity with wooden studs as the mass of the wall panels is increased

\begin{tabular}{|c|c|c|c|c|}
\hline Surface density & $\frac{\mathrm{kg}}{\mathrm{m}^{2}}$ & STC without absorption & STC with absorption & Increase in STC \\
\hline \multicolumn{5}{|c|}{$0.05 * 0.1 \mathrm{~m}$ wooden stud partition second layer screwed on } \\
\hline 29 & & 36 & 40 & 4 \\
\hline 39 & & 39 & 43 & 4 \\
\hline 49 & & 41 & 45 & 4 \\
\hline 59 & & 42 & 46 & 4 \\
\hline \multicolumn{5}{|c|}{$0.05 * 0.1 \mathrm{~m}$ wooden stud partition second layer glued on } \\
\hline 29 & & 37 & 41 & 4 \\
\hline 39 & & 41 & 45 & 4 \\
\hline 49 & & 43 & 49 & 6 \\
\hline 59 & & 46 & 52 & 6 \\
\hline
\end{tabular}

conversely the amount of sound absorption material needed for optimum STL will decrease. The effectiveness of the sound absorption material can be increased if adhesive instead of screws are used to connect the wooden studs to the wall panel. Consequently the decision about the amount of sound absorption material needed for the cavity could be based on other factors such as the thermal rating and economic cost. Although filling the last $10 \%$ of the cavity will lead to improved performance (in lightweight double leaf walls), this improvement may not be justified by the cost associated with completely filling the cavity. In situations where an increase in the STC or,$R_{w}^{\prime}$ 


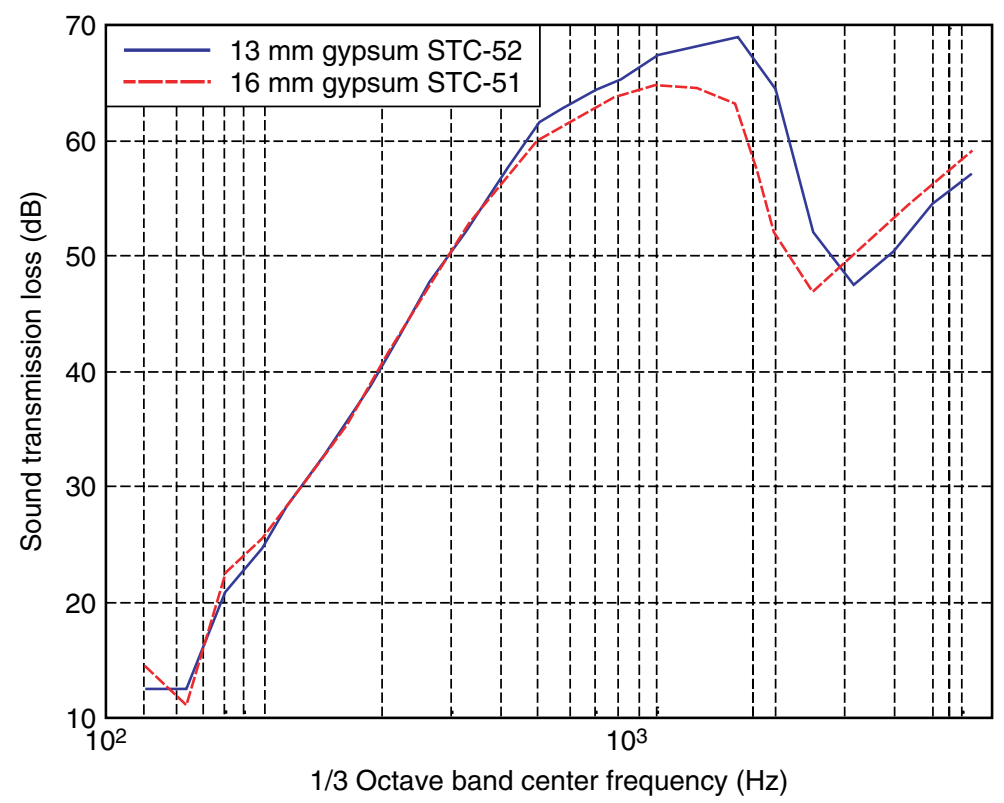

Figure 5. Reported sound transmission loss of a 13 and $16 \mathrm{~mm}$ double leaf wall with $150 \mathrm{~mm}$ steel studs at 610 centre and $150 \mathrm{~mm}$ of glass-fibre in the cavity 28.

rating can occur due to the filling of the last $10 \%$ of the wall cavity, filling this last portion of the cavity may be justified. However, if a sustainable building approach is taken, from an acoustic point of view, in terms of the STC or $R_{w}^{\prime}$ rating, completely filling the wall cavity may not be justifiable in some cases for lightweight constructions; and is not recommended for heavy double leaf wall configurations. Furthermore, filling the last $10 \%$ of the cavity may lead to an increase in the structural transmission through the frame of the material if both faces are in contact with the partitions. In such cases the performance of the wall will decrease.

\section{TYPE OF MATERIAL PLACED WITHIN THE WALL CAVITY}

The effect of the changing the material's airflow resistance, density, thickness and amount has been discussed within the previous sections. Although these discussions provided insight into how these material characteristics affect the STL a comparison of how different materials perform can be useful. The effect of using glass-fibre, mineralfibre, cellulose, polyurethane foam, polystyrene ${ }^{1}$ and polyethylene/dacron as an infill is discussed in this section. The discussion is based on the observed trends of each material in the low, middle and high frequency ranges. Within each frequency range the ranking of each material appears in descending order with each bullet point representing a separate ranking as shown in Figure 6. 
In the low frequency range polyethylene, glass-fibre and polyurethane are all ranked as performing equally well. Although Mulholland's [14] results showed that both mineralwool and polyurethane foam performed equally well and significantly better than polystyrene; Warnock's [12] and Quirt's [11] work showed that mineral-fibre didn't perform as well as glass-fibre and polyethylene in the low frequency range. Novak's[10] results showed that the higher density mineral-wool performed equally well when compared to the lower density mineral wool, glass-fibre and polyethylene/dacron; while Royar[8] observed that the STL with mineral-wool infill didn't improve much when the density was varied from 18 to $125 \mathrm{~kg} / \mathrm{m}^{3}$ Novak's [10] and Royar's [8] results with mineral-wool infills were different from Uris et al.'s [15] which showed that the low density mineral-fibre performed better than the high density material in the low frequency range. Consequently, as a result of the discrepancies in the experimental results found within the literature, mineral-fibre was ranked lower than polyurethane, polyethylene and glass-fibre. Cellulose-fibre was ranked lower than mineral wool as Warnock [12], Quirt [11] and Nova [10] each observed that cellulose performed poorly within this frequency range. Novak [10] suggested that because the mechanism by which cellulose-fibre works was totally different from that of glass-fibre and polyethylene it performed poorly in the low frequency range. Novak also noted the difficulty encountered with measuring the airflow resistance of the cellulose material due to the movements in the material. Finally, polystyrene was ranked as the worst material for the low frequency range as Mulholland's [14] observed that it hardly made any contribution to the STL and even performed worse than the empty cavity situation for part of this frequency range as shown in Figures 2 and 3.

Within the middle frequency range Mulholland's [14] experimental results showed that polystyrene performed better than polyurethane and mineral-fibre. Although polystyrene was ranked as the best material within this frequency range due to the significant improvement reported by Mulholland's [14], the use of polystyrene within the wall cavity is generally not recommended for STL purposes. All of the other materials under investigation were ranked as performing equally well within the middle
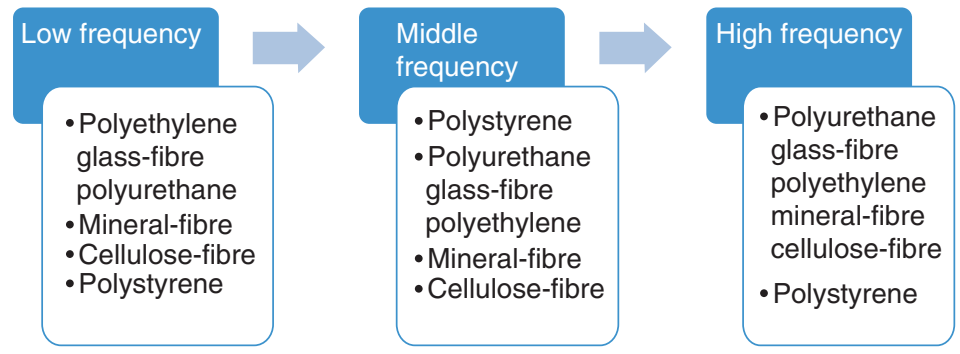

Figure 6. The ranking of the effect of different material on the STL in the low, middle and high frequency range.

\footnotetext{
${ }^{1}$ Polystyrene is not typically used as a cavity absorber to improve the STL
} 
frequency range due to the high correlation between the material's airflow resistivity and the STL as discussed by Quirt[11]. The various reported experimental results all showed that once the recommended airflow resistivity was obtained for these materials, similar STL values were derived. Furthermore, this high correlation between the airflow resistivity and the STL is the reason why polyethylene, glass-fibre, polyurethane, mineral-fibre and cellulose were all equally ranked in the high frequency range. Polystyrene performed similarly to the empty cavity within the high frequency range; as a result polystyrene was ranked as the worst performing material.

\section{SIZE OF THE WALL CAVITY}

The size of the wall cavity directly affects the resonance frequencies and pressure distribution as well as the position of the axial, tangential and oblique modes. Warnock's[12] regression lines shown in Section 2 showed a positive correlation between the STC rating and both the depth of the cavity and the spacing of the studs; both of which affect the size of the cavity. Here, the focus will be on the depth of the cavity and not on the spacing of the studs. This is due to the belief that the increase in the STL as a result of an increase in the stud spacing is due to a reduction in the number of structural transmission paths (i.e. greater spacing equates to less studs for a given wall system): On the other hand the depth of the cavity (which is controlled by the size of the studs or wall frame) will be investigated since it directly affects the volume as well as the properties of the wall cavity.

The effect of the size of the cavity on STL is dependent on whether or not sound absorption material is present within the wall cavity. Loney's [13, 27] experimental investigations showed that significant increase in the STL due to the size of the stud occurs only in the case without sound absorption material: With sound absorption material the slight increase in the STL was limited to the low frequency range. Kurra and Arditi [21] observed a similar trend with only 1-2 units increase in $R_{w}$ rating for the doubling of the cavity width with sound absorption material within the cavity as opposed to a 6-8 dB increase in the $R_{w}$ rating for the empty cavity. Green and Cameron [25] also reported that no significant increase in the STL occurred when the size of the studs were increased with sound absorption material within the cavity.

These observations are well supported by Mulholland's [14] work which showed that increasing the depth of the empty cavity from 50 to $100 \mathrm{~mm}$ resulted in a $3 \mathrm{~dB}$ mean STL increase but no increase when the depth was increased from 100 to $150 \mathrm{~mm}$. This result was similar to Utley and Mulholland's [29] investigation which showed that with different cavity depths between 100 and $200 \mathrm{~mm}$ the STL may actually decrease with an increase in depth at particular depths. Further increases in the depth of the cavity at these points then led to an increase in the STL. Utley and Mulholland concluded that this trend for different cavity depths between 100 to $200 \mathrm{~mm}$ was due to the resonances of the standing waves within the cavity. Consequently, Utley and Mulholland [29] considered a depth of $100 \mathrm{~mm}$ to be the optimum depth for their 0.035 inch $(0.9 \mathrm{~mm})$ thick aluminium double leaf wall system.

In conclusion, increasing the depth of the cavity may lead to a significant increase in the STL for the empty cavity especially at low frequencies, while smaller increases 
occur with increased cavity depth when sound absorption material is present within the cavity. The effectiveness of increasing the cavity depth is dependent on the resonances of the standing waves within the cavity; consequently a decrease in the STL can actually occur at certain cavity depths when the depth of the empty cavity is increased.

\section{LOCATION OF THE SOUND ABSORPTION MATERIAL}

The effect of the location of the sound absorption material within the wall cavity for the partially filled case has been investigated by some authors. Gösele [6] acknowledged Meyer's [30] suggestion that placing sound absorption material along the margins of the wall cavity could be used to prevent the occurrence of resonances within the cavity; the improvement over the empty cavity situation was noted by Gösele who however concluded that it is not a substitute for completely filling the cavity.

The concept of placing the sound absorption material along the margins of the cavity as well as along other strategic positions within the cavity was also investigated by Ford [19]. These results showed that placing the sound absorption material along the margins of the cavity resulted in a reduction in the low frequency performance of the wall system when compared to when the same amount of material was distributed over the entire volume of the cavity. On the other hand Loney's [13] investigation showed little difference in the STL when the sound absorption material was moved closer to the wallboard on the source side, receiving side and directly to the centre of the cavity. Quirt's [11] results also showed negligible change in the STL when the sound absorption material was moved from the centre of the cavity towards one of the faces of the wall panel. However, Quirt's measurements did indicate that the position of the absorption material does matter in the partially filled case; since the STL was consistently lower when the material was placed on the top or bottom of the wall cavity when compared to when the same amount was placed as one complete layer in the centre.

Further insight into the effect of the location of the sound absorption material within the wall cavity can be deduced from Bolton et al.'s. [31] investigation. Bolton et al. [31] measured the STL of an aluminium double leaf wall with polyurethane foam within the cavity and found that having the sound absorption material unbound to the wall panel was generally preferred to having it bound. However, if improvement in the low frequency range is required then attaching the sound absorption material to the wall panel increases its stiffness and causes the first resonance to shift to a higher frequency range which results in an increase in the STL [31].

In conclusion the location of the sound absorption material within the cavity for the partially filled case does affect the STL. It is recommended that the sound absorption material be placed unbound from the panel in the centre of the wall cavity as one complete unit as opposed to along the lining or on the top/bottom area of the cavity. If improvement in the low frequency region is of prime concern, bonding sound absorption material to the face of one of the panels may be effective. 


\section{SUMMARY AND CONCLUSIONS}

The influence of the wall cavity on the sound transmission loss based on experimental evidence has been discussed. This discussion showed that the airflow resistivity of porous sound absorption material gives the best indication of how effective the material will be in enhancing the STL. The research from many authors has indicated that an airflow resistivity of approximately $5000 \mathrm{Ns} / \mathrm{m}^{4}$ is needed to damp the modes within the cavity while a material density of at least approximately $40 \mathrm{~kg} / \mathrm{m}^{3}$ is recommended. For both the airflow resistivity and density caution must be taken in increasing these parameters as such increases may lead to an increase in the rigidity in some materials with the additional risk of an increase in structural transmission.

The effect of the materials thickness to cavity ratio and the amount of sound absorption material within the cavity were also discussed. Previous work on these issues has shown that the STL increases with increased thickness of the material up until a certain thickness to cavity depth ratio; while the optimum amount of sound absorption material is dependent on both the mass of the wall panels and the type of structural connection used.

With regard to the size of the cavity, type and location of the material utilized, the literature suggests that significant improvement in STL can be gained by increasing the size of the empty cavity; while smaller improvement occurs when the size of the cavity is increased with sound absorption material within the cavity. The best material to be used is dependent on the frequency range of interest with the STL being sensitive to the location of the material placed within the wall cavity.

Finally the investigation has revealed that a wide variety of conclusions were obtained by different authors concerning the role of the cavity and the properties of any associated sound absorption material on the sound transmission loss through double wall systems. Consequently recommendations about the ways in which sound transmission through cavity systems can be improved should always be qualified with regard to the specific frequency range of interest, type of sound absorption material, wall panel and stud characteristics.

\section{REFERENCES}

[1] Fausti P, Pompoli R, Smith R. An intercomparison of laboratory measurements of airborne sound insulation of lightweight plasterboards Journal of Building Acoustics 1999;6:127-40.

[2] Jacobsen F, Ding H. Observations of the systematic deviations between the results of the conventional method and the sound intensity method of measuring transmission loss Inter-noise 96. Liverpool 1996.

[3] Ding H, Jacobsen F. Comparison of sound transmission loss between the sound intensity method and the conventional two room method in the laboratory Internoise 94. Yokohama-Japan 1994.

[4] Lai JCS, Burgess MA, Narang PP, Mikl K. Transmission loss measurements: Comparisons between intensity and conventional methods Inter-noise 91. Sydney, Australia 1991. 
[5] Shravage P, Sachin J, Karanth N. Effect of intrinsic parameters on the sound absorption and transmission loss: A parametric study Noise-Con 2010. Baltimore, Maryland 2010.

[6] Gösele VK, Gösele U. Einfluß der Hohlraumdämpfung auf die Steifigkeit von Luftschichten bei Doppelwänden (Influence of cavity volume damping on the stiffness of air layers in double walls). Acustica 1977;38(3):159-66.

[7] Narang PP. Effect of fiberglass density and flow resistance on sound transmission loss of cavity plasterboard walls. Noise Control Engineering Journal 1993;40(3):215-20.

[8] Royar J. Different influence of mineral wool airflow resistivity on performance of sound transmission loss constructions. Inter-noise 2007. Istanbul, Turkey 2007.

[9] Narang PP. Material parameter selection in polyester fibre insulation for sound transmission and absorption Applied Acoustics 1995;45:335-58.

[10] Novak RA. Sound insulation of lightweight double walls Applied Acoustics 1992;37:281-303.

[11] Quirt JD, Warnock ACC. Influence of sound-absorbing material, stud type and spacing, and screw spacing on sound transmission through double-panel wall specimen Inter-noise 93. Leuven-Belgium 1993.

[12] Warnock ACC, Quirt JD. Sound transmission through gypsum board walls Internoise 95. Newport Beach, CA, USA, 1995.

[13] Loney W. Effect of cavity absorption on the sound transmission loss of steel-stud gypsum wallboard partitions. Journal of the Acoustical Society of America 1971;49(2):385-90.

[14] Mulholland KA. Sound insulation measurements on a series of double plasterboard panels with various infills Applied Acoustics 1971;4:1-12.

[15] Uris A, Llopis A, Llinares J. Effect of the rockwool bulk density on the airborne sound transmission of lightweight double walls. Applied Acoustics 1999;58:327-31.

[16] Northwood TD. Transmission loss of plasterboard walls Ottawa: National Research Council Canada, 1966.

[17] Uris A, Cervera F, Llinares J. Sound transmission loss of lightweight double walls filled with polyurethane foam. Noise Control Engineering Journal 2000;48(1):5-7.

[18] Irvine LK, Richards LR. Acoustics and noise control handbook for architects and builders. Malabar Florida: Krieger publishing company, 1998.

[19] Ford RD, Lord P, Williams PC. The influence of absorbent linings on the transmission loss of double-leaf partitions. Journal of Sound and Vibration 1967;5(1):22-28.

[20] Bazley EN. The airborne sound insulation of partitions London Her majesty's stationery office 1966. 
[21] Kurra S, Arditi D. Determination of sound transmission loss of multilayered elements part 2: An experimental study Acustica 2001;87:592-603.

[22] Hongisto V, Lindgren M, Helenius R. Sound insulation of double walls - an experimental parametric study. Acta Acustica United With Acustica 2002;88(6):904-23.

[23] Uris A, Llopis A, Llinares J. Technical note: The influence of insulation thickness and number of layers of gypsum wall board on lightweight partition sound transmission loss. Noise Control Engineering Journal 2001;49(5):238-40.

[24] Green WD, Cameron WS. Sound transmission loss of gypsum wallboard partitions. Report \#1. Unfilled steel stud partitions Journal of the Acoustical Society of America 1982;71(1):90-96.

[25] Green WD, Cameron WS. Sound transmission loss of gypsum wallboard partitions. Report \#2. Steel stud partitions having cavity filled with glass fiber batts Journal of the Acoustical Society of America 1982;71(4):902-07.

[26] Green WD, Cameron WS. Sound transmission loss of gypsum wallboard partitions. Report \#3. 2*4 in. wood stud partitions Journal of the Acoustical Society of America 1982;71(4):908-14.

[27] Loney W. Effect of cavity absorption and multiple layers of wallboard on soundtransmission loss of steel-stud partitions. Journal of the Acoustical Society of America 1973;53(6):1530-34.

[28] Halliwell RE, Nightingale TRT, Warnock ACC, Birta JA. Gypsum board walls: Transmission loss data Internal report IRC-IR-761, National Research Council Canada 1998.

[29] Utley WA, Mulholland KA. The transmission loss of double and triple walls Applied Acoustics 1968;1:15-20.

[30] Meyer E. Die Mehrfachwand als akustisch-mechanische drosselkette (Multiple walls as acoustic-mechanical inductor). Elektr Nachrichtentech 1935;12:393.

[31] Bolton JS, Shiau NM, Kang YJ. Sound transmission through multi-panel structures lined with elastic porous materials Journal of Sound and Vibration 1996;191(3):317-47. 
